\title{
Environmental Factors in the Etiology of Parkinson's Disease
}

\author{
Caroline M. Tanner, Biao Chen, Wen-Zhi Wang, Man-Ling Peng, Zho-Lin Liu, \\ Xue-Ling Liang, Li Chiung Kao, David W. Gilley and Bruce S. Schoenberg*
}

\begin{abstract}
Parkinson's disease (PD) has been proposed to result from the interaction of aging and environment in susceptible individuals. Defective metabolism of debrisoquine, inherited as an autosomal recessive, has been associated with this susceptibility. In 35 PD patients and 19 age-matched controls, no significant differences in debrisoquine metabolism were found, although a trend to impaired metabolism was noted in patients with disease onset $\leqslant 40$. Foci of PD patients were associated with rural living and well water drinking, or rural living coupled with market gardening or wood pulp mills. In a questionnaire survey, patients with PD onset $\leqslant$ age 47 were significantly more likely to have lived in rural areas and to have drunk well water than those with onset $\geqslant$ age $54(p \leqslant 0.01)$. Because of population mobility in North America, a case-control study designed to test environmental, occupational, dietary and other proposed risk factors for PD was conducted in China, where the population is more stationary and the environment more stable. No significant differences in incidences of head trauma, smoking or childhood measles were found between patients and controls.
\end{abstract}

RÉSUMÉ: Facteurs environnementaux dans l'étiologie de la maladie de Parkinson. Il a déjà été proposé que la maladie de Parkinson MP est le résultat de l'interaction du vieillissement et de l'environnement chez des individus qui y sont susceptibles. Un défaut dans le métabolisme de la débrisoquine, dont l'hérédité est autosomale récessive, a été associé à cette susceptibilité. Nous avons étudié le métabolisme de la débrisoquine chez 35 patients atteints de la MP et 19 contrôles appariés pour l'âge. Aucune différence significative dans le métabolisme de la débrisoquine n'a été constatée, quoique une tendance à un métabolisme diminué a été notée chez les patients dont l'âge de début est $\leqslant \grave{\mathrm{a}} 40$ ans.

Des foyers de patients parkinsoniens étaient associés à la vie à la campagne et l'absorption d'eau de puits, ou à la vie à la campagne associée au jardinage commercial ou aux moulins de pâtes et papier. Dans une enquête effectuée par questionnaire, les patients dont la MP avait commencé $\leqslant$ à 47 ans étaient significativement plus susceptibles d'avoir vécu à la campagne et d'avoir bu de l'eau de puits que ceux dont la maladie avait commencé $\geqslant$ à 54 ans $(\mathrm{p}<0.01)$.

Pour identifier des facteurs de risque environnementaux spécifiques, on doit comparer les expositions de toute la vie entre des patients atteints de MP et des contrôles appariés pour l'âge. La mobilité de la population et le changement constant des techniques agricoles et industrielles limitent nécessairement la réalisation d'une telle étude en Amérique du Nord. Une étude cas-témoin conçue dans le but de vérifier certains facteurs de risque déjà proposés pour la MP tels l'environnement, l'occupation, la diète et autres, a été réalisée en Chine, la population de ce pays étant plus fixe et l'environnement plus stable. Nous n'avons constaté aucune différence significative dans les incidences de traumatismes crâniens, de fumeur ou de rougeole infantile entre les patients et les contrôles dans cette maladie.

Can. J. Neurol. Sci. 1987; 14:419-423

Apart from the well-described increase in prevalence of Parkinson's Disease (PD) after the age of $40,{ }^{1,2}$ no single factor has been definitively associated with an increased risk for the development of PD. Individual factors proposed to play a role in the pathogenesis of PD include: aging, heredity, toxic exposures and stress or trauma. In 1983, Calne and Langston ${ }^{3}$ proposed that PD may be the combined product of a neurotoxic environmental insult with normal aging. Barbeau ${ }^{4}$ proposed a heritable susceptibility to environmental toxins, leading to the development of PD if an appropriate toxin is environmentally present. These hypotheses have yet to be rigorously tested. This paper will review the evidence for and against several proposed risk factors for $\mathrm{PD}$, and will include the results of some recent studies of these hypotheses.

\section{Heredity}

Gowers ${ }^{5}$ described a family history of PD in $15 \%$ of his patients and a $16 \%$ prevalence of PD in the relatives of affected patients was reported in a 1904 series from New York. ${ }^{6}$ Later, Mjönes ${ }^{7}$ reported a 22\% familial occurrence in Sweden, although he allowed tremor alone for the diagnosis of PD, and thus may have included some cases of essential tremor, which is known to have a hereditary basis. None of these reports compared their results to expected prevalence figures for the community at large. Kondo, Kurland and Schull ${ }^{8}$ studied sibships from Rochester, Minnesota, and reviewed Mjönes' data, eliminating questionable patients, to determine a heritability of $79 \%$ for the former and $91 \%$ for the latter series. They proposed a multifactorial inheritance, with development of PD dependent on the

*Deceased July 14, 1987.

From the Departments of Neurological Sciences (Dr. Tanner, Ms. Kao) and Psychology (Mr. Gilley), Rush-Presbyterian-St. Luke's Medical Center, Chicago, lL; Department of Neurology, Sun Yat Sen Medical University (Drs. Chen, Liu and Liang), Guongzhou, China; Beijing Neurosurgical Institute (Drs. Peng and Wang), Beijing, China; and the Neuroepidemiology Branch, National Institute of Neurological and Communicative Disorders and Stroke (Dr. Schoenberg), National Institutes of Health, Bethesda, Maryland

Reprint requests to: Dr. Caroline M. Tanner, Department of Neurological Sciences, Rush-Presbyterian-St. Luke's Medical Center, Chicago, Illinois, U.S.A. 
interaction of genetic and environmental factors. Martin and colleagues $^{9}$ in Minnesota found an increased frequency of PD among parents and siblings of patients, compared to those of spouse controls, and suggested a polygenic inheritance with a threshold. Myrianthopoulos ${ }^{10}$ reported an increased prevalence of PD in families of patients with phenothiazine-induced parkinsonism, in contrast to families of phenothiazine-treated controls without parkinsonism. Barbeau and colleagues ${ }^{11,12}$ postulated specific subgroups of patients with heritable PD, comprising altogether $14 \%$ of all patients. A recent report from Mexico described a similar familial distribution in parkinsonian patients. ${ }^{13}$ However, in none of these studies were all "affected" family cases verified by neurologist examination. Also, the occurrence of family aggregates in a common disorder such as PD does not necessarily indicate a hereditary pathogenesis.

Duvoisin and his colleagues ${ }^{14}$ argued against a genetic etiology for PD after comparing the prevalence of PD in the siblings of 85 PD cases with that of spouses and spouse siblings. All subjects were examined by a neurologist. The siblings of patients did not have an increased risk for PD. Evidence against a hereditary basis for PD is also provided by studies of twins, at least one of whom has PD. Only one of 43 monozygotic and none of 19 dizygotic twins studied by Ward and his colleagues ${ }^{15}$ were concordant for PD, despite a mean age of 64 at the time of examination. Marttila and colleagues ${ }^{16}$ identified affected twins through public health records. Only one of 40 twin pairs was concordant for PD. Finally, efforts to identify specific HLA patterns ${ }^{17}$ or blood groups ${ }^{18}$ within PD patients have produced no correlation between these hereditable traits and PD.

Barbeau and his associates ${ }^{19}$ also reported an abnormality of a specific hepatic cytochrome $\mathrm{P} 450$ enzyme system in parkinsonian patients. This metabolic defect is characterised by a slowed metabolism of debrisoquine, defined as a ratio of urinary debrisoquine/4-OH-debrisoquine $>1$ ("metabolic ratio", or MR). In a study of 40 patients and 40 controls, significantly more PD patients were poor metabolizers of debrisoquine. All of the PD patients with PD onset before the age of 40 were poor metabolizers. The investigators postulated that poor metabolizers may be less efficient at detoxifying environmental toxins, and thus more likely to develop PD. However, the use of other drugs was not controlled, but instead peaks of drugs known to interfere with debrisoquine determination were "subtracted" from the chromatographic pattern. A further caution in interpreting these data is the possibility that concurrent drug use may influence debrisoquine metabolism, making the results of the test in drug-treated patients meaningless.

Recently, Comella and her associate ${ }^{20}$ studied debrisoquine metabolism in 35 PD patients (mean age 61 years) and 19 spouse controls (mean age 57 years). No subject had received amantadine, anticholinergic drugs or tricyclic antidepressants for at least 4 weeks prior to the study. In accordance with the method used by Barbeau et al ${ }^{19}$ subjects were given $10 \mathrm{mg}$ debrisoquine sulphate and urine was collected over an 8 hour period. Urinary debrisoquine and $4 \mathrm{OH}$ debrisoquine concentrations were determined by gas chromatography with mass spectroscopy. Debrisoquine metabolism was not different between patients and controls. Seven of the 11 patients with PD onset before the age of $40(64 \%)$ but only $36 \%$ of age-matched controls were slow metabolizers. These results were not statistically significant $(p=0.07$, chi square), although this may be the result of small sample size. The relationship of impaired debrisoquine metabo- lism to PD remains uncertain. Future studies should concentrate on drug-free cases and controls.

\section{Environmental Causes}

The inconclusive results of studies of heredity in PD have led many investigators to postulate an important role for environmental factors in the development of PD. Proposals for specific putative environmental toxins have been influenced by agents known to cause secondary parkinsonism, such as viruses and metals. Smoking has often been reported to be less common in $\mathrm{PD}$, and this has also been proposed to relate to its etiology. The evidence supporting each of the various proposed environmental factors will be reviewed separately.

\section{Environmental Toxins}

Discrete populations have been observed to develop parkinsonian syndromes as the result of environmental exposure to several toxic agents. An example of an environmental exposure producing a parkinsonian syndrome is provided by descriptions of parkinsonism resulting from manganese intoxication..$^{21,22}$ In Guam, low environmental levels of calcium and magnesium and ingestion of a dietary toxin have both been proposed to underlie the focus of parkinsonism-dementia. ${ }^{23,24}$ These disorders, however, are both clinically and pathologically distinct from $P D$, suggesting that a different, although possibly related, pathogenesis must underlie PD.

Recently, a small number of intravenous drug abusers developed parkinsonism which was clinically very similar to PD, with the exception that profound disability occurred within days to weeks of exposure ${ }^{25,26} \mathrm{~A}$ meperidine derivative, MPTP (1-methyl-4-phenyl-1,2,3,6-tetrahydropyridine) was identified as the toxic agent. Administration of this agent to a variety of animal species has produced behaviora ${ }^{27}$ and pathologic ${ }^{28}$ changes similar to PD. One human autopsy study has also resembled PD but without definitive Lewy bodies. ${ }^{25}$ Signs of parkinsonism in persons with industrial exposures to MPTP have also been reported ${ }^{29}$ MPTP is structurally similar to a variety of compounds which may be present in an industrialized environment. ${ }^{30}$

The fact that exogenous agents can have selective central nervous system toxicity and produce syndromes similar to PD has heightened research interest in environmental factors which may be related to the pathogenesis of PD. Rajput and colleagues ${ }^{31}$ recently reported a cluster of patients with PD onset under the age of $\mathbf{4 0}$ in rural Saskatchewan. All patients drank water from wells, and a possible toxin in well water was proposed. Barbeau and Roy ${ }^{32}$ identified PD patients in Quebec through the records of various health care agencies, and plotted their distribution. They found foci of higher prevalence in rural areas specializing in market gardening, and others in association with wood mills. Aquilonius and Hartvig ${ }^{33}$ used pharmaceutical records of levodopa use to identify the regional distribution of PD in Sweden. They found a high incidence of l-dopa use in one county, in which saw and paper mills and steel alloy industries were the prevalent types of industry, and postulated heavy metals as possible toxins underlying $P D$.

Tanner ${ }^{34}$ reasoned that environmental exposure to a particular toxin might result in an earlier onset of PD in exposed patients. To test Rajput's observation, 95 outpatients with PD (52 men and 43 women) were questioned concerning well water use. Mean age at PD onset was 56.2 years (range: $31-87$ ). Before the onset of PD, 54 patients had used well water as their major 
source of drinking water for at least two years (mean 21.3; range 2-72). Significantly more patients with an age of $P D$ onset less than 47 had used well water for two or more years, compared to those with older onset $(p<0.03$, Fisher exact).

To explore further the possibility that well water drinking might predispose to an earlier age of PD onset, a questionnaire was distributed to 32,000 members of the United Parkinson Foundation..$^{34}$ Respondents were asked to complete a detailed life history, documenting place of residence, population, and source of drinking water. Of the 1,500 questionnaires received by May 6, 1985, 1,100 were from patients who identified themselves as suffering from "idiopathic Parkinson's disease". These were then classified by age at onset (as specified by the respondent). Based on the distribution of age at $\mathrm{PD}$ onset in the author's institution, "young onset" patients had disease onset at age 47 or younger. "Average and old onset" patients had disease onset at age 54 or later. Questionnaires from all 253 young onset patients and every third average and old onset patient $(n=259)$ were analysed. Patients with disease onset between 48 and 53 were not studied. Drinking well water for more than one year was more common among young onset patients than average and old ( chi square $=8.16, \mathrm{df}=1, \mathrm{p}<0.01$ ). Similarly, living in a rural environment (population 1,000 or less) was more common in young onset patients (chi square $=7.31$, $\mathrm{df}=1, \mathrm{p}<\mathbf{0 . 0 1}$ ). However, there are many potential sources of error in this study. The use of members of an organization as potential subjects and the low response rate both suggest that the subjects may not be representative of $P D$ patients as a whole. Diagnosis and age at disease onset are determined only by patient report, and may be erroneous. These data should be considered to be preliminary.

\section{Trauma and Stress}

Emotional and physical trauma are among the earliest postulated etiologies of PD. Gowers attributed more than one third of his cases to such factors, ${ }^{5}$ and Charcot observed that sudden emotional shocks commonly preceded PD. ${ }^{35}$ Two recent studies have suggested that extreme stress or trauma may predispose to $\mathrm{PD}$. Gibberd and Simmonds ${ }^{36}$ reported a parkinsonism prevalence of $512 / 100,000$ in men who had been prisoners of war in the Far East, as compared to controls who had served in the same regions at the same time without imprisonment. Symptoms of parkinsonism began decades after imprisonment, and resembled $\mathrm{PD}$ in all respects. Ward and colleagues, ${ }^{15}$ in an investigation of twins, one of whom had PD, found head trauma to be significantly higher in affected twins, although the trauma was often minor, and without loss of consciousness.

The relationship of head trauma to $P D$ has recently been assessed in a case control study of 100 PD patients and 200 age ( \pm 3 years) and sex matched neurologic controls, conducted in the People's Republic of China (PRC). All cases were selected from the outpatient neurology clinics at two major teaching hospitals in Beijing and one in Guangzhou. Controls were selected from the same institution as the reference case, from among patients with the following diagnoses: tension headache (15.5\%), migraine headache $(32.5 \%)$, cervical spondylosis ( $31 \%)$, Bell's palsy $(5.5 \%)$, low back pain $(2.5 \%)$, sciatica $(7 \%)$, spinal stenosis $(5.5 \%)$ and herniated nucleolus pulposis $(0.5 \%)$. All potential cases and controls were examined independently by two neurologists, and included only if each accepted the subject. Twenty-three cases were women, and the remainder men, rep- resenting a sex distribution similar to that observed in a community-based survey of PD in the PRC. ${ }^{37}$ Mean age of the cases was 57.2 years (range: $31-77$ ) and of the controls was 56.8 years (range: 31-77). Mean age of PD onset was 51.5 years (range: 30-75). Mean Hoen and Yahr stage for PD cases was 3.1 (range: 1-5), and mean disease duration was 5.6 years (range: .5-22). Since demented subjects would be expected to provide inaccurate data, subjects were excluded if scoring below 12 on a brief mental status examination performed by the Chinese neurologist. Patients and controls were questioned by a Chinese neurologist to determine whether or not they had suffered a head injury, and the date of the injury. Loss of consciousness was not required to diagnose head injury. In order to avoid including injuries which resulted from parkinsonian postural reflex impairment, only injuries occurring one year or more before the onset of PD symptoms (as described by the patient) were considered. For controls, injuries occurring one year or more before the age of PD onset in the reference case were included. Thirteen percent of subjects with PD and 5\% of controls had head trauma. There was no significant difference in the frequency of head trauma between cases and controls (odds ratio 3.00; chi square 1.28; calculated using the extended Mantel-Haenszel estimate for 2 matched controls). ${ }^{38}$ Despite the elevated relative risk, the fact that this difference was not significant may represent the small sample size rather than that head trauma has no importance to the development of PD. However, head trauma has also been implicated as a risk factor in Alzheimer's disease, brain tumours, motor neuron disease and multiple sclerosis, and this may reflect a problem of selective recall bias.

\section{Smoking}

A large number of studies have observed an inverse relationship between smoking and the development of PD. These have included case-control studies using practice-based ${ }^{39}$ and neighbourhood ${ }^{40}$ controls, as well as comparisons in twins. ${ }^{15.41}$ In contrast, no difference in smoking history was found in a casecontrol review of medical records in Rochester. ${ }^{42}$ Decreased smoking in PD may be explained by a physiologic or psychologic predisposition to dislike smoking, or by a true protective effect of cigarette smoking against PD. Golbe and colleagues ${ }^{43}$ tested this hypothesis in a mail questionnaire study, and found no relationship between antecedent smoking and severity or progression of disease, concluding that physiologic or psychologic dislike was a better explanation of decreased smoking in PD.

The relationship of tobacco use to Parkinson's disease was assessed in the case-control study in the PRC described above. Patients were questioned about the types of tobacco used, and asked to provide a yearly estimate of numbers of cigarettes smoked daily. These estimates were subsequently analysed as pack-years, so that 20 cigarettes per day for one year equalled one pack-year. Forty-one percent of the patients and $49.5 \%$ of the controls had ever smoked cigarettes. This difference was not significant (odds ratio $=.67$; chi square $=.386$; calculated using the extended Mantel-Haenszel estimate for 2 matched controls). ${ }^{38}$ There was no significant difference between PD cases and controls in mean pack-years smoked (22.5 and 22.0, respectively). Similarly, PD cases were not significantly different from controls when compared by smoking habits at the time of disease onset, at ten years before onset, at 20 years before 
onset, and at the time of the interview. In PD patients, smokers and non-smokers did not differ in mean age of onset, duration of illness or Hoehn and Yahr stage ( $p>0.2)$. These data indicate a slightly lower incidence of smoking in PD, but this difference did not reach statistical significance, perhaps reflecting the small sample size. These results suggest that low smoking rates among PD patients in other studies may be an epiphenomenon, rather than representing a direct protective effect of smoking.

\section{Viruses}

The observation that encephalitis lethargica, presumably a viral infection, could cause parkinsonism, coupled with the observation that other viral encephalitides occasionally result in parkinsonism, led to the postulate that latent virus infections might underlie PD as well. ${ }^{44}$ Marttila and colleagues found no difference in influenza virus antibody titres between PD cases and controls. ${ }^{45}$ The same investigators found that antibody titres to Herpes Simplex virus (HSV) were elevated in serum, but not CSF, of 441 PD patients when compared to 443 controls, ${ }^{17}$ although the degree of antibody response did not correlate with PD severity. The investigators postulated that HSV might be etiologically related to $\mathrm{PD}$, or that the antibody response may be an epiphenomenon. Further investigation of these possibilities remains to be done.

In a prospective postal survey of US men recruited as college students (between the years 1916 and 1950), Sasco and Paffenbarger ${ }^{46}$ compared PD patients to 4 matched controls. These researchers reported a negative correlation between measles infection before college and PD. Whether this reflected a higher prevalence of adult or inapparent neonatal measles infection in PD cases, or a true increased risk of PD in those without childhood infection could not be determined. Since diagnosis was determined only by physician's (not neurologist's) statement, diagnostic accuracy is also uncertain.

The relationship of childhood measles infection to the development of Parkinson's disease has recently been tested in the case control study conducted in the PRC (described above). No differences were found between cases (38\% childhood measles) and controls (37\% childhood measles) for measles infection.

Other studies have provided negative data concerning the relationship of viral infection to PD. Case control studies in twins ${ }^{15,40}$ and comparisons of incidence rates in Rochester after swine flu vaccination ${ }^{2}$ found no identifiable infectious risk factor. Finally, PD has not been transmitted to animals by injection of affected brain tissue. ${ }^{3}$ Current evidence is inconclusive concerning a relationship of viral infection to PD, and more extensive verification of postulated associations is necessary.

\section{Conclusion}

No study has demonstrated that a single environmental agent can account for a majority of PD cases. At best, the available evidence suggests that there may be an elevated risk for PD associated with some environmental factors. The reported low prevalence of $\mathrm{PD}$ in relatively non-industrialized countries is consistent with a hypothesis involving man-made toxins, which would be present in lower concentrations in these countries. However, PD, has been present since at least $1817,{ }^{47}$ so that any single toxin would also have to have been present since that time. This makes modern agricultural chemicals which are similar to MPTP less likely to be the sole toxins. Alternatively, many different agents, all of which induce neurotoxicity by mechanisms similar to those of MPTP, may underlie the illness.

More likely, a variety of factors may contribute to the development of PD. These factors could include combinations of genetic predisposition, aging and environment, and could vary between persons. Answers to the hypotheses presented here will require further case-control studies and observations of international incidence and prevalence patterns, in combination with descriptive series which attempt to verify the presence of proposed subgroups of patients, some of whom might have different etiologies of their disease.

\section{ACKNOWLEDGEMENTS}

This work was supported in part by grants from the United Parkinson Foundation and the Boothroyd Foundation, Chicago, Illinois.

\section{REFERENCES}

1. Mutch WJ, Dingwall-Fordyce I, Downie AW, et al. Parkinson's disease in a Scottish city. Brit Med J 1986; 192: 534-536.

2. Rajput AH, Offord KP, Beard MC, et al. Epidemiology of parkinsonism: Incidence, classification, and mortality. Ann Neurol 1984; 16: 278-282.

3. Calne DB, Langston JW. Aetiology of Parkinson's disease. Lancet 1983; ii: 1457-1459.

4. Barbeau A. Etiology of Parkinson's disease: A research strategy. Can J Neurol Sci 1984; 11: 24-28.

5. Gowers WR. A manual of diseases of the nervous system. American edition. Philadelphia: Blakisten, Son \& Co., 1888.

6. Hart TS. Paralysis agitans: Some clinical observations based on the study of 219 cases seen at the clinic of Professor M. Allen Starr. J Nerv Ment Dis 1904; 31 : 177-188.

7. Mjönes H. Paralysis agitans: A clinical and genetic study. Acta Psychiatr Neurol 1949; 54 (Suppl): 1-94.

8. Kondo K, Kurland LT, Schull WJ. Parkinson's disease: genetic analysis and evidence of a multifactorial etiology. Mayo Clin Proc 1973; 48: 465-475.

9. Martin WE, Young WI, Anderson VE. Parkinson's disease: A genetic study. Brain 1973; 96: 495-506.

10. Myrianthopoulos NC, Waldrop IN, Vincent BL. A repeat study of hereditary predisposition in drug-induced parkinsonism. In: Barbeau A, Brunett JR, eds. Progress in Neurogenetics. Amsterdam, Excerpta Medica 1969; 486-491.

11. Barbeau A, Pourcher E. New data on the genetics of Parkinson's disease. Can J Neurol Sci 1981; 9: 53-60.

12. Barbeau A, Roy M. Familial subsets in idiopathic Parkinson's disease. Can J Neurol Sci 1984; 11: 144-150.

13. Alonso ME, Otero E, D'Regules R, et al. Parkinson's disease: A genetic study. Can J Neurol Sci 1986; 13: 248-251.

14. Duvoisin RC, Gearing IR, Schweitzer MR, et al. A family study of Parkinsonism. In: Barbeau A, Brunette JR, eds. Progress in Neurogenetics. Excerpta Medica Foundation 1969; 492-496.

15. Ward CD, Duvoisin RC, Ince SE, et al. Parkinson's disease in 65 pairs of twins and in a set of quadruplets. Neurology $1983 ; 33$ : 815-24.

16. Marttila RJ, Kaprio J, Koskenvuo M, et al. Finnish Parkinson's disease twin study: Preliminary results. Upsala J Med Sci 1986; (Supp 43): 93.

17. Rinne UK. Recent Advances in Research on Parkinsonism. In: Marttila RJ, ed. Proceedings of the 22nd Scandinavian Congress of Neurology. Acta Neurologica Scandinavica 1978;(Suppl 67): $77-113$.

18. Strang RR. The ABO blood-group distribution of 450 Swedish patients with Parkinson's disease. Neurology 1966; 16: 1051-1052.

19. Barbeau A, Roy M, Paris S, et al. Ecogenetics of Parkinson's disease: 4-hydroxylation of debrisoquine. Lancet 1985; ii: 1213-1215.

20. Comella CL, Tanner CM, Goetz CG, et al. Debrisoquine metabolism in Parkinson's disease. Neurology 1987; (suppl 1): 261-262. 
21. Mena I, Marin O, Fuenzalida S. Chronic manganese poisoning: Clinical picture and manganese turnover. Neurology 1976; 17: 128-136.

22. Emara AM. Chronic manganese poisoning in the dry battery industry. Brit J Indust Med 1971; 28: 78-84.

23. Garruto RM, Gajdusek C. Factors provoking the high incidence of amyotrophic lateral sclerosis and parkinsonism-dementia of Guam: Deposition and distribution of toxic metals and essential minerals in the central nervous system. In: Gottfries CG, ed. Normal Aging, Alzheimer's Disease and Senile Dementia. Aspects of Etiology, Pathogenesis, Diagnosis and Treatment. Editions de l'Universite de Bruxelles, Bruxelles 1985; 69-81.

24. Chen K, Chase TN. Parkinsonism-dementia. In: Vinken P, Bruyn G, Klawans HL, eds. Handbook of Clinical Neurology, Vol 49, Chapter 8. Elsevier Science, Amsterdam. 1986: 167-183.

25. Langston JW, Ballard P, Tetrud JW, et al. Chronic parkinsonism in humans due to a product of meperidine-analog synthesis. Science 1982; 219: 979-980.

26. Tetrud JW, Langston JW. Early parkinsonism in humans due to MPTP exposure. Neurology 1986; 36 (Suppl): 308.

27. Burns RS, Phillips JM, Chiueh CC, et al. The MPTP-treated monkey model of Parkinson's disease. In: Markey SP, Castagnoli N, Trevor AJ, Kopin IJ, eds. MPTP: A neurotoxin producing a parkinsonian syndrome. Academic Press, Orlando, 1986; 23-42.

28. Forno LS, Langston JW, DeLanney LE, et al. Locus ceruleus lesions and eosinophilic inclusions in MPTP-treated monkeys. Ann Neurol 1986; 20: 449-455.

29. Langston JW, Ballard PA. Parkinson's disease in a chemist working with 1-methyl-4-phenyl-1,2,5,6-tetrahydropyridine. New Engl J Med 1983; 309: 310.

30. Solomon H, D'Amato RJ. Predicting Parkinson's disease. Nature 1985; 317: 198-199.

31. Rajput AH, Uitti RJ, Stern W, et al. Early onset of Parkinson's disease in Saskatchewan - environmental considerations for etiology. Can J Neurol Sci 1986; 13: 312-316.

32. Barbeau A, Roy M. Genetic susceptibility, environmental factors and Parkinson's disease. VIII International Symposium on
Parkinson's Disease; New York, 1985; 13

33. Aquilonius SM, Hartvig P. Utilization of antiparkinson drugs in Sweden. Upsala J Med Sci 1986; (Supp 43): 93.

34. Tanner CM. Influence of environmental factors on the onset of Parkinson's disease (PD). Neurology 1986; 36 (Suppl): 215.

35. Charcot JM. Lectures on the Diseases of the Nervous system. Vol I (translated by G. Sigeran). London: The New Sydenham Society, 1887.

36. Gibberd FB, Simmonds JP. Neurological disease in ex-far-east prisoners of war. Lancet 1980; ii: 135-137.

37. Li S, Schoenberg BS, Wang C, et al. A prevalence survey of Parkinson's disease and other movement disorders in the People's Republic of China. Arch Neurol 1985; 42: 655-657.

38. Schlesselman JJ, Stolley PD. Case-control studies: Design, conduct, analysis. New York: Oxford University Press, 1982.

39. Godwin-Austen RB, Lee PN, Marmot MG, et al. Smoking and Parkinson's disease. J Neurol Neurosurg Psychiat 1982; 45: 577-581.

40. Baumann RJ, Jameson HD, McKean HE, et al. Cigarette smoking and Parkinson's disease: 1 . A comparison of cases with matched neighbors. Neurology 1980; 30: 839-843.

41. Bharucha NE, Stokes L, Schoenberg BS, et al. A case-control study of twin pairs discordant for Parkinson's disease: A search for environmental risk factors. Neurology 1986; 36: 284-288.

42. Rajput AH. Epidemiology of Parkinson's disease. Can J Neurol Sci 1984; 11: 156-159.

43. Golbe L1, Cody RA, Duvoisin RC. Smoking and Parkinson's disease: Search for dose-response relationship. Arch Neurol 1986; 43: 774-778.

44. Moore G. Influenza and Parkinson's disease. Public Health Reports 1977; 92: 79.

45. Marttila RJ, Halonen P, Rinne UK. Influenza virus antibodies in parkinsonism. Arch Neurol 1977; 34: 99-100.

46. Sasco AJ, Paffenbarger RS. Measles infection and Parkinson's disease. Am J Epidemiol 1985; 133: 1017-1031.

47. Parkinson J. An essay on the shaking palsy. London: Whittingham \& Rowland, 1817. 